\title{
Collection efficiency of the soot-particle aerosol mass spectrometer (SP-AMS) for internally mixed particulate black carbon
}

\author{
M. D. Willis ${ }^{1}$, A. K. Y. Lee ${ }^{1}$, T. B. Onasch ${ }^{2}$, E. C. Fortner ${ }^{2}$, L. R. Williams ${ }^{2}$, A. T. Lambe ${ }^{2}$, D. R. Worsnop ${ }^{2}$, and \\ J. P. D. Abbatt ${ }^{1}$ \\ ${ }^{1}$ Department of Chemistry, University of Toronto, Toronto, Ontario, Canada \\ ${ }^{2}$ Aerodyne Research, Inc., Billerica, Massachusetts, USA \\ Correspondence to: M. D. Willis (megan.willis@mail.utoronto.ca) and T. B. Onasch (onasch@aerodyne.com)
}

Received: 13 May 2014 - Published in Atmos. Meas. Tech. Discuss.: 26 May 2014

Revised: 17 October 2014 - Accepted: 6 November 2014 - Published: 18 December 2014

\begin{abstract}
The soot-particle aerosol mass spectrometer (SPAMS) uses an intra-cavity infrared laser to vaporize refractory black carbon ( $\mathrm{rBC}$ ) containing particles, making the particle beam-laser beam overlap critical in determining the collection efficiency (CE) for $\mathrm{rBC}$ and associated non-refractory particulate matter (NR-PM). This work evaluates the ability of the SP-AMS to quantify rBC and NR-PM mass in internally mixed particles with different thicknesses of organic coating. Using apparent relative ionization efficiencies for uncoated and thickly coated $\mathrm{rBC}$ particles, we report measurements of SP-AMS sensitivity to NR-PM and rBC, for Regal Black, the recommended particulate calibration material. Beam width probe (BWP) measurements are used to illustrate an increase in sensitivity for highly coated particles due to narrowing of the particle beam, which enhances the CE of the SP-AMS by increasing the laser beam-particle beam overlap. Assuming complete overlap for thick coatings, we estimate CE for bare Regal Black particles of 0.6 \pm 0.1 , which suggests that previously measured SP-AMS sensitivities to Regal Black were underestimated by up to a factor of 2. The efficacy of the BWP measurements is highlighted by studies at a busy road in downtown Toronto and at a nonroadside location, which show particle beam widths similar to, but greater than that of bare Regal Black and coated Regal Black, respectively. Further BWP measurements at field locations will help to constrain the range of $\mathrm{CE}$ for fresh and aged rBC-containing particles. The ability of the SP-AMS to quantitatively assess the composition of internally mixed particles is validated through measurements of laboratorygenerated organic coated particles, which demonstrate that
\end{abstract}

the SP-AMS can quantify $\mathrm{rBC}$ and NR-PM over a wide range of particle compositions and $\mathrm{rBC}$ core sizes.

\section{Introduction}

Incomplete combustion of fossil fuels, bio-fuels and biomass emit teragram quantities of anthropogenic black carbon to the troposphere every year (Bond et al., 2007, 2013). Aerosol containing black carbon is an important absorber of short wave radiation in the atmosphere, with the ability to affect the energy balance at the surface and within the troposphere (Ramanathan and Carmichael, 2008). Black carboncontaining particles are estimated to be the third largest contributor to anthropogenic global warming, after carbon dioxide and methane (Bond et al., 2013). However, the magnitude of their direct effects on radiative balance may become even more significant when black carbon is internally mixed with other aerosol components such as sulphate, nitrate and organic species (Adachi et al., 2010; Jacobson, 2001), though the importance of this enhancement for ambient aerosol remains an open question (Cappa et al., 2012; Lack et al., 2012). The physical and chemical complexity of these particles compounds the uncertainty associated with the impacts of black carbon on global and regional climate change and human health (Seinfeld, 2008; Jansen et al., 2005).

A variety of measurement techniques have been used to quantify atmospheric black carbon. These include direct techniques, such as the single particle soot photometer (SP2) that uses laser induced incandescence to quantify refractory black carbon (rBC) and indirect methods using 
opticaltechniques, sample oxidation, or oxidation combined with optical methods (Bond et al., 2013; Lack et al., 2014). When aerosols contain a small black carbon mass fraction, reported mass concentrations from a range of measurement techniques can differ significantly (up to $80 \%$ ) (Bond et al., 2013). This large range in black carbon mass loadings can be partially attributed to measurement bias, most often for optical methods, associated with the presence of other absorbing species in the aerosol. These measurement uncertainties can make it difficult to understand the spatial and temporal trends and the climate impacts of black carbon.

The soot-particle aerosol mass spectrometer (SP-AMS) is a recently developed instrument that combines a nearinfrared laser system for volatilization of $\mathrm{rBC}$ with the Aerodyne high-resolution time-of-flight AMS (DeCarlo et al., 2006) to quantify aerosol components (Onasch et al., 2012). Near-IR laser vaporization and electron impact ionization facilitate mass spectral detection of light-absorbing $\mathrm{rBC}$ and the simultaneous measurement of non-refractory species associated with rBC. Detection of rBC and NR-PM depends upon the ability of $\mathrm{rBC}$ to absorb the IR energy and produce a heating effect significant enough to volatilize the $\mathrm{rBC}$ coating material and, upon further heating, the rBC itself. The SP-AMS has been shown to respond linearly and reproducibly to laboratory generated $\mathrm{rBC}$ particles (Regal Black (Cabot R400) and flame generated soot) (Onasch et al., 2012). However, in contrast to the Regal Black particles generally used for SP-AMS calibration, freshly emitted particulate black carbon tends to be smaller and less compact (i.e. lower mass-mobility exponent, Cross et al., 2010). Over time these small particles grow and become internally mixed with organic and inorganic species through condensation and coagulation. With ageing, changes in chemical composition and physical properties of $\mathrm{rBC}$ particles affect their atmospheric lifetime, radiative properties, and their ability to act as cloud condensation nuclei and as ice nuclei (Liu et al., 2013; Bond et al., 2013). Therefore, it is crucial that the SP-AMS is able to quantify the extent of particle coating and the rBC mass loading. The ability to simultaneously detect $\mathrm{rBC}$ and species that condense on it with comparable accuracy is crucial for three reasons; first, to assess the rates at which black carbon processing occurs in the atmosphere; second, to understand the role that such internally mixed particles may play as cloud nuclei; and third, to assess direct effects on solar radiation.

Previous research has applied the linear response of the SP-AMS to measure the size-resolved chemical composition of rBC-containing particles during roadside measurements of traffic related pollutants (Massoli et al., 2012), and to characterize the $\mathrm{rBC}$ mixing state for its relation to black carbon absorption enhancement (Cappa et al., 2012). However, the effect of $\mathrm{rBC}$ mixing with NR-PM on the collection efficiency of the SP-AMS laser vaporizer has not been explicitly addressed. In this work, we first examine the effect of rBC-particle coating on the SP-AMS sensitivity to the rec-

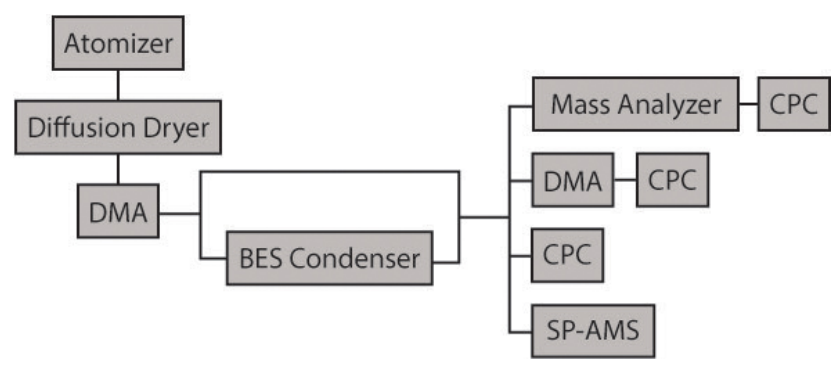

Figure 1. Laboratory schematic showing the basic particle generation, coating and characterization components. Experiments were conducted independently at the University of Toronto (UofT) and Aerodyne Research, Inc. (ARI) with similar set-ups, see text for details.

ommended calibration material, Regal Black. Secondly, we address differences in collection efficiency for bare and internally mixed $\mathrm{rBC}$ particles with beam width probe (BWP) measurements to demonstrate particle beam narrowing that occurs due to coating. Finally, using measured sensitivities for laboratory-generated particles, we demonstrate that the SP-AMS can quantify the fraction of $\mathrm{rBC}$ in coated particles over a wide range of internally mixed compositions.

\section{Experimental}

\subsection{Particle generation and coating}

Experiments were conducted at the University of Toronto (UofT) and at Aerodyne Research, Inc. (ARI) with similar experimental set-ups. A general experimental schematic is shown in Fig. 1. In both cases, rBC containing particles were generated from a water suspension of Regal Black (RB) (Regal 400R pigment, Cabot Corp.), with concentrations ranging from 10 to $1000 \mathrm{mg} \mathrm{L}^{-1}$ in de-ionized water $(18 \mathrm{M} \Omega-\mathrm{cm}$, TOC $<4 \mathrm{ppb})$, using a constant output atomizer (TSI Inc., model 3076). The polydisperse aerosol flow was dried with a diffusion drier containing silica gel $(<20 \% \mathrm{RH})$ and directed to a differential mobility analyser (TSI Inc. model 3081) for size selection. The monodisperse aerosol was characterized "bare" (nascent) or after coating with bis(2-ethylhexyl)sebacate (BES) via condensation in a thermally controlled condenser.

The University of Toronto coating apparatus consisted of a $1.3 \mathrm{~cm}$ outer diameter, $30 \mathrm{~cm}$ long glass tube containing BES. The sample line was connected to the coating region via $0.63 \mathrm{~cm}$ diameter glass inlets. The temperature of the coating region was controlled using heating tape, monitored using a thermocouple and varied from room temperature up to $125^{\circ} \mathrm{C}$. Aerosol carrier flow through the coating region was $450 \mathrm{~cm}^{3} \mathrm{~min}^{-1}$. The ARI coating apparatus consisted of a $60 \mathrm{~cm}$ long, $1.3 \mathrm{~cm}$ outer diameter glass tube wrapped in heating tape and temperature controlled using an Omega PID controller and a thermocouple. The tube has two temperature 
zones ( $\sim 30 \mathrm{~cm}$ each) and was operated with the downstream zone set to $\sim 20^{\circ} \mathrm{C}$ less than the upstream zone. The temperature of the upstream zone was varied from room temperature to $150^{\circ} \mathrm{C}$. The flow through the coating tube was $750 \mathrm{~cm}^{3} \mathrm{~min}^{-1}$. Experimental conditions are summarized in Table 1.

\subsection{Particle characterization}

The size selected bare and coated $\mathrm{rBC}$ particles were characterized for particle mass using a mass analyser (aerosol particle mass analyser (APM model 3600, Kanomax Inc.) or centrifugal particle mass analyser (CPMA, Cambustion), Olfert and Collings, 2005), number concentration using a condensation particle counter (CPC, TSI Inc., model 3776 and 3022a), and contributions from doubly charged particles using a scanning mobility particle sizer (SMPS. TSI Inc., model 3936). SMPS measurements were used to determine appropriate solution concentrations to use in the atomizer, such that doubly charged particles accounted for less than $10 \%$ of the total particle mass. Particle number concentration was monitored before and after coating, and used to monitor particle loss or homogeneous nucleation. The mass analyser was scanned using both the rotational speed and voltage to measure the size resolved mass distribution for coated and bare particles. From the mass analyser measurements of bare and coated Regal Black particles we define the mass ratio of organic coating to Regal Black $\left(R_{\mathrm{Org} / \mathrm{RB}}=\operatorname{mass}_{\mathrm{BES}} /\right.$ mass $\left._{\mathrm{RB}}\right)$ and the mass fraction of Regal Black $\left(f_{\mathrm{RB}}=\operatorname{mass}_{\mathrm{RB}} /\left(\operatorname{mass}_{\mathrm{BES}}+\operatorname{mass}_{\mathrm{RB}}\right)\right)$, where $\operatorname{mass}_{\mathrm{BES}}=\operatorname{mass}_{\mathrm{RB}, \text { coated }}-\operatorname{mass}_{\mathrm{RB}}$.

\subsection{The soot-particle aerosol mass spectrometer (SP-AMS)}

The soot-particle aerosol mass spectrometer (SP-AMS) is an Aerodyne high-resolution AMS equipped with an infrared laser vaporization module similar to that of the single particle soot photometer (Droplet Measurement Technologies) as described in detail by Onasch et al. (2012). SP-AMS instruments contain both the traditional tungsten vaporizer and the IR-laser vaporizer, and can be operated with both tungsten and IR-laser vaporizers on or with only the tungsten vaporizer on. In order to operate with the IR-laser vaporizer only, the tungsten vaporizer must be removed because its lowest possible temperature is $\sim 200^{\circ} \mathrm{C}$ due to heating by the filament.

In brief, the SP-AMS laser vaporization module uses a continuous wave intra-cavity $1064 \mathrm{~nm} \mathrm{Nd:YAG} \mathrm{laser,} \mathrm{sit-}$ uated perpendicular to the particle beam, that allows vaporization and subsequent detection of $\mathrm{rBC}$ species (Onasch et al., 2012). The width of the laser beam (fundamental transverse mode, TEM00, with Gaussian profile) is dictated by the length of the lasing cavity and the curvature of the optics, which are fixed in SP-AMS instruments. Particles are focused with an aerodynamic lens into a narrow beam which crosses the IR laser beam. Particles containing rBC absorb IR energy and are heated, first vaporizing non-refractory (NR) coatings (estimated temperature $<600^{\circ} \mathrm{C}$ ) and then vaporizing the $\mathrm{rBC}$ (estimated temperature $\sim 4000^{\circ} \mathrm{C}$ Onasch et al., 2012). Neutral gas phase analytes are ionized using $70 \mathrm{eV}$ electron impact ionization. Three SP-AMS instruments were used in this study (UofT SN 215-121, ARI SN 215-039 and 215-130), all of which are time-of-flight mass spectrometers operated in $\mathrm{V}$-mode with both the tungsten vaporizer $\left(\sim 600^{\circ} \mathrm{C}\right)$ and the laser vaporizer simultaneously, unless otherwise noted.

Particle beam alignment with the tungsten vaporizer and the IR laser beam was confirmed preceding these experiments and IR laser power was optimized for saturation of the rBC signal. The physical distance between the centre of the tungsten vaporizer and the vertical position of maximum sensitivity for Regal Black in the IR laser was $\leq 0.5 \mathrm{~mm}$. Data acquisition alternated between mass spectrum (MS) and particle time-of-flight (pToF) modes. Data were analysed using the AMS analysis software Squirrel version $1.51 \mathrm{H}$ and Pika version 1.10H. Signals of $\mathrm{rBC}$ from Regal Black were quantified by the sum of $\mathrm{C}_{1}^{+}$to $\mathrm{C}_{9}^{+}$peaks, using high resolution $(R \sim 2000$ at $m / z 28)$ MS data. The average ratio of $\mathrm{C}_{1}^{+}$to $\mathrm{C}_{3}^{+}(0.6)$, obtained from bare Regal Black, was used to correct the $\mathrm{C}_{1}^{+}$peak intensity for interference from nonrefractory species in coated particles. Signals from refractory oxygen containing species can arise during the vaporization of $\mathrm{rBC}$ and can contribute to signals at $\mathrm{CO}^{+}$and $\mathrm{CO}_{2}^{+}$ (Corbin et al., 2013; Onasch et al., 2012). The signals arising from $\mathrm{CO}^{+}$and $\mathrm{CO}_{2}^{+}$were not included in the organic loading if it accounted for greater than $10 \%$ of the total organic signal, since the appropriate chemical fragmentation of these species arising from Regal Black was not quantified in this work.

For comparison to mass analyser derived mass fractions of Regal Black $\left(f_{\mathrm{RB}}\right)$ in coated particles, chemical identification and quantification was carried out with each SP-AMS instrument. The SP-AMS derived $f_{\mathrm{RB}}$ (or $R_{\mathrm{Org} / \mathrm{RB}}$ ) was determined through quantification of $\mathrm{rBC}$ and coating, taking into account NR-PM already present on Regal Black as follows:

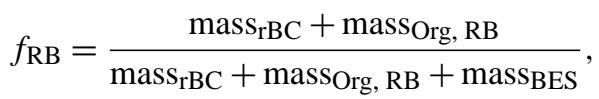

where mass $\mathrm{Org}, \mathrm{RB}$ is the mass of organic species present on bare Regal Black.

\subsection{Particle beam width measurements}

Each SP-AMS was equipped with a beam width probe (BWP) consisting of a vertical wire of 0.46 or $0.41 \mathrm{~mm}$ in width (UofT and ARI, respectively). The BWP wire was oriented perpendicular to the laser beam axis and stepped across the particle beam parallel to the laser axis (horizontally). 
Table 1. Summary of particle generation systems.

\begin{tabular}{lll}
\hline & UofT apparatus & ARI apparatus \\
\hline DMA & TSI model 3081 & TSI model 3081 \\
DMA sample flow $(\mathrm{sccm})$ & 450 & 300 \\
DMA sheath flow $(\mathrm{sccm})$ & 4500 & 3000 \\
Coating tube diameter $(\mathrm{cm})$ & 1.3 & 1.3 \\
Coating tube length $(\mathrm{cm})$ & 30 & 60 \\
Coating tube flow rate $(\mathrm{sccm})$ & 450 & 750 \\
Coating tube temperature range $\left({ }^{\circ} \mathrm{C}\right)$ & $25-125$ & $25-150$, with two temperature zones $(\Delta T=20)$ \\
\hline
\end{tabular}

As detailed in Huffman et al. (2005), the BWP wire blocks a fraction of sampled particles from reaching the vaporizer at each step. By analysing the results from multiple wire steps across the particle beam, the particle beam divergence can be determined. In the horizontal orientation, the laser beam produces uniform vaporization of $\mathrm{rBC}$, thus allowing direct measurement of $\mathrm{rBC}$ particle beam widths. Particle beam widths $(\sigma)$ in this work are determined by fitting a onedimensional Gaussian profile to the measured transmission profile as a function of the distance the BWP wire travels along the horizontal axis of the laser beam. These widths are slightly different widths than those derived by Huffman et al. (2005), where a two-dimensional Gaussian profile was assumed for the particle beam and the tungsten vaporizer geometry was explicitly included in their modelling. BWP measurements were also carried out by rotating the BWP such that the wire was oriented parallel to the laser beam axis and could be stepped across the particle beam perpendicular to the laser beam (vertically). Measurements in this orientation can provide some insight into the effective laser beam width for rBC. Note that the UofT SP-AMS was operated without the tungsten vaporizer during these vertical BWP measurements. See Supplement Fig. S1 for an illustration of BWP orientation for particle and laser beam width measurements.

\section{Results and discussion}

\subsection{The effect of rBC-particle coating on SP-AMS collection efficiency}

\subsubsection{SP-AMS calibration}

The goal of this section is to examine the effect of $\mathrm{rBC}$ mixing state on SP-AMS sensitivity to $\mathrm{rBC}$ and associated NR-PM. To do so, we measure the apparent ionization efficiency of $\mathrm{rBC}$ and organic coating material relative to nitrate $\left(\mathrm{RIE}_{\mathrm{rBC}}\right.$, app and $\mathrm{RIE}_{\mathrm{Org}}$, app $)$ for a variety of particle coating thicknesses and compare these observations to uncoated values. The relative ionization efficiency, defined in previous work (Jimenez et al., 2003; Onasch et al., 2012), is applied to quantify the mass concentration of a particu- late species. Using the mass based ionization efficiency for nitrate $\left(\mathrm{mIE}_{\mathrm{NO}_{3}}\right.$, in units of ions per picogram) the mass concentration of species "s" can be determined as follows:

$C_{\mathrm{s}}=\frac{1}{\mathrm{CE}_{\mathrm{S}} \cdot \mathrm{RIE}_{\mathrm{s}} \cdot \mathrm{mIE}_{\mathrm{NO}_{3}} \cdot Q} \sum_{i} I_{\mathrm{s}, i}$,

where $C_{\mathrm{s}}$ is the mass concentration of species "s," $\mathrm{RIE}_{\mathrm{s}}=$ $\mathrm{mIE} / \mathrm{mIE}_{\mathrm{NO}_{3}}, Q$ is the flow rate, $\mathrm{CE}_{\mathrm{s}}$ is the species specific collection efficiency, and each $I_{\mathrm{s}, \mathrm{i}}$ is an ion signal associated with species "s." The apparent mass based ionization efficiency is dependent on the collection efficiency (i.e. $\mathrm{RIE}_{\mathrm{s}, \mathrm{app}}=\mathrm{RIE} \cdot \mathrm{CE}_{\mathrm{s}}$ ) for the particular particle type, which is given by the product of terms associated with loss due to the aerodynamic lens $\left(E_{\mathrm{L}}\right)$, beam divergence $\left(E_{\mathrm{S}}\right)$, and particle bounce $\left(E_{\mathrm{B}}\right)$ off of the tungsten vaporizer $(\mathrm{CE}=$ $E_{\mathrm{L}} \cdot E_{\mathrm{S}} \cdot E_{\mathrm{B}}$ ) (Huffman et al., 2005). For particles with unit lens transmission, the most important loss mechanism when considering the laser vaporization module of the SP-AMS is beam divergence, such that $\mathrm{CE} \cong E_{\mathrm{S}}$ (Onasch et al., 2012).

$\mathrm{RIE}_{\mathrm{rBC}}$, app and $\mathrm{RIE}_{\mathrm{Org}}$, app values were determined from independent measurements of $\mathrm{mIE}_{\mathrm{rBC}}$, app, $\mathrm{mIE}_{\mathrm{Org} \text {, app }}$ and $\mathrm{mIE}_{\mathrm{NO}_{3}}$. Good agreement was observed between $\mathrm{RIE}_{\mathrm{rBC}}$, app values obtained from bare Regal Black over the particle size range of $250-400 \mathrm{~nm}$, which suggests minimal difference in collection efficiency for these uncoated particles.

\subsubsection{The effect of $\mathrm{rBC}$-particle coating}

$\mathrm{RIE}_{\mathrm{rBC}}$, app and $\mathrm{RIE}_{\mathrm{Org}}$, app values were measured over a range of BES coating thicknesses, with the mass ratio of BES to Regal Black $\left(R_{\mathrm{Org} / \mathrm{RB}}\right)$ ranging from 0 to 6 (corresponding to a mass fraction of Regal Black, $f_{\mathrm{RB}}$, ranging from 1 to 0.15 ). Particles with $200-500 \mathrm{~nm}$ mobility diameters, characterized in terms of their per particle masses and number concentrations, were used to ensure unit lens transmission $\left(E_{\mathrm{L}}=1\right)$. Figure 2a demonstrates that as $R_{\mathrm{Org} / \mathrm{RB}}$ increases, the apparent sensitivity to $\mathrm{rBC}$ increases by approximately a factor of 2 , for two SP-AMS instruments, and within the uncertainties of our measurements appears to saturate at $R_{\mathrm{Org} / \mathrm{RB}}>3$. A similar trend is shown in Fig. $2 \mathrm{~b}$ for the BES coating from each SP-AMS instrument. A comparable increase in sensitivity with particle coating was also observed 

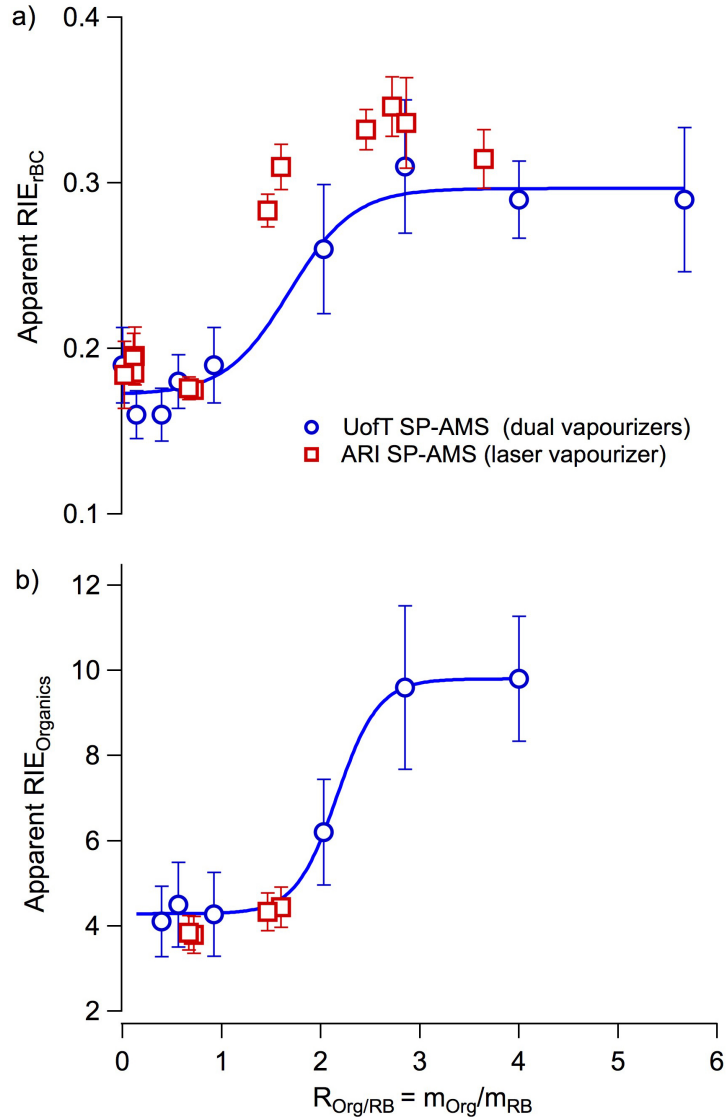

Figure 2. (a) $\mathrm{RIE}_{\mathrm{rBC}}$, app measured as a function of BES coating thickness, demonstrating an increase in sensitivity that appears to reach saturation at approximately $R_{\mathrm{Org} / \mathrm{RB}}=3$. $\mathrm{RIE}_{\mathrm{rBC}}$, app values at $R_{\mathrm{Org} / \mathrm{RB}}=0$ were obtained using 200 and $300 \mathrm{~nm}\left(d_{\mathrm{m}}\right)$ particles. Data from two instruments is included: UofT (circles) and ARI data with the laser vaporizer only (squares, SN 215-130). (b) RIE $\mathrm{Org}_{\text {, app }}$ measured as a function of BES coating thickness, demonstrating a similar increase with coating thickness. The blue solid lines represent a best fit to the UofT SP-AMS data used in subsequent analysis (Sect. 3.5).

with a third SP-AMS instrument (see Fig. S2); however, particle mass analyser measurements were not available during this experiment so the data were not included in Fig. 2. The difference in sensitivity enhancement evident in Fig. 2a between the two instruments could be due to differences in the final coated particle size or to differences in the uniformity of particle coating provided by each coating apparatus, both of which could result in differences in particle focusing in the aerodynamic lens and the resulting particle beam-laser beam overlap. The possibility of homogeneously nucleated organic particles, which cannot be neglected in these experiments, could also lead to differences in the overall RIE enhancement.

The relatively large values of RIE Org, app $_{\text {observed in this }}$ work for BES were higher than the recommended value of 1.4 for all sampled organics from ambient sources (Al- farra et al., 2004). As noted in Jimenez et al. (2003) individual organic molecules may exhibit different RIE values, including values greater than 1.4. Utilizing the results published in Jimenez et al. (2003) (Fig. 6), organic hydrocarbon compounds have an apparently higher RIE than highly oxygenated organic compounds (RIE $\sim 2$ for hydrocarbons vs. $\sim 1.3$ for oxygenated compounds). BES has a relatively low $\mathrm{O}: \mathrm{C}$ ratio $(4: 26 \sim 0.15)$, and thus may exhibit an RIE similar to hydrocarbons up to $\sim 2$. For these data, the apparent RIE (defined as SP-AMS measured ions divided by the difference of the coated to uncoated per particle mass from the mass analyser) measured for BES under thin coating conditions are highly uncertain due to the difference term in the denominator, which goes to zero with thin coatings. Under thicker coating conditions, the observed RIE $_{\text {Org, app val- }}$ ues are significantly higher than 2 and increase with coating thickness. Reasons for this may be due to differences between the laser and tungsten vaporizers and could include; (1) an enhanced ionization efficiency for gas phase molecules generated in the laser vaporizer due to their position relative to the filament; (2) an improved ion extraction efficiency of ions originating from neutral gas-phase molecules vaporized at the laser vaporizer, due to their position in the ion chamber; or (3) a collection efficiency on the tungsten vaporizer of less than one $\left(E_{\mathrm{b}}<1\right)$ for organics on $\mathrm{rBC}$ particles. The fact that an $\mathrm{RIE}_{\mathrm{Org} \text {, app }}>2$ for coated particles is observed not only with dual vaporizers, but also with the laser vaporizer alone may suggest an enhanced sensitivity to species volatilized from the laser vaporizer. In addition, the fractional increase in $\mathrm{RIE}_{\mathrm{Org}}$, app is larger than that of $\mathrm{RIE}_{\mathrm{rBC}}$, app, which may indicate the relevance of possibility (3), above, since organic species are volatilized from both vaporizers in this instrumental configuration. Further work is required to fully understand the differing responses to $\mathrm{rBC}$ and NR-PM in the SP-AMS.

The observed dependence of SP-AMS sensitivity on particle coating thickness (Fig. 2) is likely caused by decreased particle beam divergence with coating, resulting in greater particle beam-laser beam overlap. The saturation behaviour shown in Fig. 2 can be used to estimate collection efficiency $\left(E_{S}\right)$ for bare Regal Black particles and for the organic species on thinly coated Regal Black particles. With the assumption that the sensitivity measured at saturation (i.e. highly coated particles) corresponds to complete particle beam-laser beam overlap $\left(E_{\mathrm{S}}=1\right.$ and $\mathrm{RIE}_{\mathrm{rBC}}$, app $=$ $\mathrm{RIE}_{\mathrm{rBC}}$ ), then $E_{\mathrm{S}}$ can be inferred by dividing $\mathrm{RIE}_{\mathrm{rBC}}$, app (RIE ${ }_{\text {Org, app }}$ ) values for the bare (nascent) Regal Black by the average maximum value observed in each instrument for coated particles $\left(\mathrm{RIE}_{\mathrm{rBC}}\right.$, app and $\mathrm{RIE}_{\mathrm{Org}}$, app $)$. From the data sets presented in Fig. 2, for bare (nascent) Regal Black, an $E_{\mathrm{S}}$ value of $0.6 \pm 0.1$ was determined. This result indicates that Regal Black calibrations used in the past, with $\mathrm{mIE}_{\mathrm{rBC}}$ of $\sim 150 \pm 25$ ions pg $^{-1}$ and corresponding $\mathrm{RIE}_{\mathrm{rBC}}$ of $0.2 \pm 0.1$ (Onasch et al., 2012), are underestimated by approximately a factor of 2 . 


\section{2 rBC particle beam divergence}

In this section, the impact of particle coating on SP-AMS collection efficiency is explored using particle beam width measurements. Non-spherical particles produce more divergent particle beams compared to spherical particles, owing to lift and drag on irregularly shaped particles. As non-spherical rBC-containing particles are coated with a liquid organic species, they become more spherical in shape (e.g. Cross et al., 2010). Therefore, a change in rBC-containing particle shape could affect particle beam divergence enough to alter the extent of particle beam-laser beam overlap, thus altering the collection efficiency $\left(E_{\mathrm{s}}\right)$. To investigate this difference in sensitivity with particle coating, the change in particle beam width was measured as a function of coating thickness with a beam width probe (BWP).

In this context, signal transmission is defined as the signal intensity at a given BWP position relative to that of an unblocked beam, normalized to particle number concentration. With a BWP centred in the particle beam, a lower signal transmission will indicate a narrower beam since a larger fraction of particles are blocked by the BWP wire. Figure 3 compares signal transmission versus BWP position curves for $200 \mathrm{~nm}$ uncoated Regal Black, BES coated Regal Black particles $\left(R_{\mathrm{Org} / \mathrm{RB}} \sim 3\right)$ and $300 \mathrm{~nm}$ ammonium nitrate (as an example of a well focused beam), each fit to a 1-D Gaussian distribution. The standard deviation $(\sigma)$ of this distribution is used to describe the particle beam width (i.e. $4 \sigma$, or $\pm 2 \sigma$, defines $95.4 \%$ of the particle beam width). As shown in Table 2 BWP measurements indicate that the particle beam narrows from $\sigma \sim 0.4 \mathrm{~mm}$ for bare, 200 and $300 \mathrm{~nm}$ Regal Black particles to approximately $0.1-0.2 \mathrm{~mm}$ (ARI and UofT measurements, respectively) when the particles are coated with BES $\left(R_{\mathrm{Org} / \mathrm{RB}} \sim 3\right)$. The differences in beam width measured in the two experiments likely arise from differences in the final coated particle size $\left(\sim 375 \mathrm{~nm}\right.$ and $d_{\mathrm{va}} \sim 280 \mathrm{~nm}$, see Table 2). The beam width for these coated Regal Black particles approaches that of pure $230 \mathrm{~nm}$ BES particles $(\sigma=0.12 \mathrm{~mm})$ (Huffman et al., 2005). However, it should be noted that 1D Gaussian fits to BWP curves at low $\sigma$ (i.e. a well focused beam) may overestimate the particle beam width (Huffman et al., 2005).

Figure 4a demonstrates the relationship between sensitivity to $\mathrm{rBC}$, particle beam width and coating thickness. With a BWP centred in the Regal Black particle beam, signal transmission decreases as $R_{\mathrm{Org} / \mathrm{RB}}$ increases (i.e. the particle beam width decreases as coating thickness increases). Furthermore, with the BWP positioned outside of the particle beam, $\mathrm{mIE}_{\mathrm{rBC}}$, app increases as $R_{\mathrm{Org} / \mathrm{RB}}$ increases. These two observations suggest that as $\mathrm{rBC}$ particles become more coated the particle beam-laser beam overlap becomes more complete, giving rise to enhanced signal intensity for $\mathrm{rBC}$

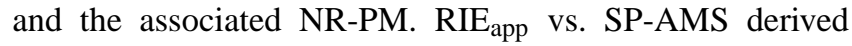
$R_{\mathrm{Org} / \mathrm{RB}}$ plots for this data set, similar to those in Fig. 2, are presented in Fig. S2. Figure $4 b$ demonstrates that rBC

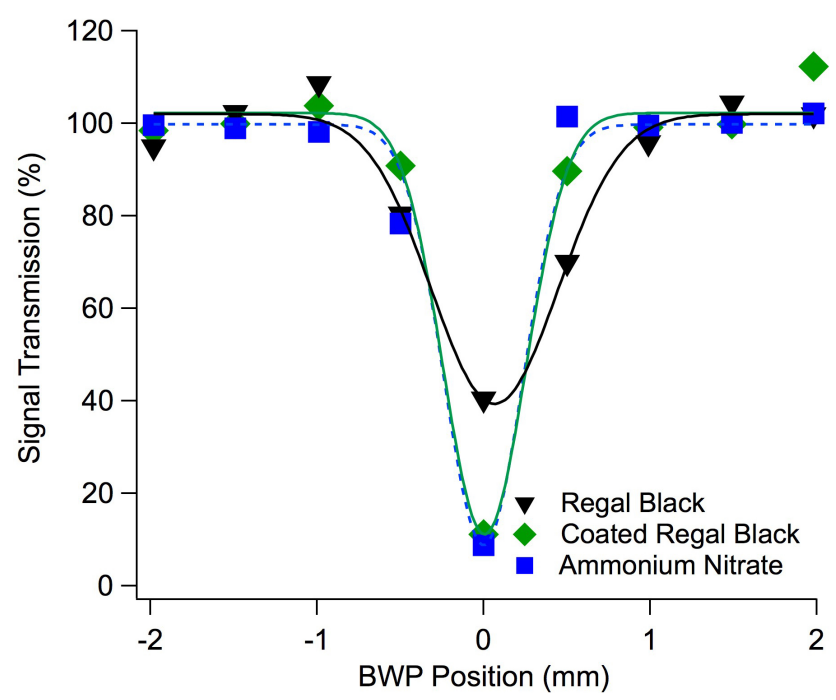

Figure 3. Comparison of BWP signal transmission (signal intensity relative to that of an unblocked beam, normalized to particle number concentration) traces for $200 \mathrm{~nm}$ bare $\left(f_{\mathrm{RB}}=1\right)$, BES coated $\left(R_{\mathrm{Org} / \mathrm{RB}}=3\right)$ Regal Black and $300 \mathrm{~nm}$ ammonium nitrate particles vaporized using the tungsten vaporizer as an example of a well focused beam. Data from the UofT SP-AMS.

and organic signal transmission both decrease due to particle coating, with an approximately one-to-one relationship. This concept is discussed further in Sect. 3.5.

\subsection{Measure of effective laser width for $\mathrm{rBC}$}

To aid in assessing the importance of incomplete laser beamparticle beam overlap for SP-AMS quantification of $\mathrm{rBC}$, an upper limit for the effective laser beam width was estimated and compared to ambient particle beam width measurements.

When the SP-AMS is operated without the tungsten vaporizer and the BWP is positioned such that the wire could be moved vertically (perpendicular to the laser beam axis), some information can be gained about the effective width of the laser beam in much the same manner as is done for particle beam widths. Since the resulting BWP position versus signal transmission curve is affected not only by the true laser beam effective width but also by the particle beam and the BWP wire width, these measurements only allow for estimation of an upper limit for the effective SP-laser width for rBC. Figure 5 demonstrates that with a $0.46 \mathrm{~mm}$ BWP centred in front of the IR laser an average of $97 \pm 2 \%$ of the $\mathrm{rBC}$ signal was attenuated. From this information and the projected BWP wire width (see Fig. 5) the effective laser beam width $(4 \sigma)$ can be estimated as less than $0.73 \mathrm{~mm}$. Therefore, the effective laser beam width $(\sigma)$ is at most $0.18 \mathrm{~mm}$. The narrowness of the effective laser beam width highlights the importance of determining $E_{\mathrm{S}}$ for accurate quantification of rBC mass loadings. Further measurements are required to unambiguously determine the effective IR laser beam width. 
Table 2. Summary of particle beam width measurements.

\begin{tabular}{|c|c|c|}
\hline Particle type & Beam width $\sigma(\mathrm{mm})$ & Reference \\
\hline Flame soot & 0.77 & Huffman et al. (2005) \\
\hline Ambient rBC (roadside, Toronto) & $0.46 \pm 0.03$ & this work \\
\hline 300 nm Regal Black & $0.40 \pm 0.08$ & this work \\
\hline 200 nm Regal Black & $0.39 \pm 0.04$ & this work \\
\hline Ambient rBC (non-roadside, Toronto) & $0.26 \pm 0.04$ & this work \\
\hline 300 nm Nitrate (tungsten vaporizer) & $0.22 \pm 0.05$ & this work \\
\hline Coated Regal Black (UofT, 150 nm core $^{\mathrm{a}}$ ) & $0.23 \pm 0.08$ & this work \\
\hline Coated Regal Black (ARI, 300 nm core ${ }^{b}$ ) & $0.11 \pm 0.03$ & this work \\
\hline $230 \mathrm{~nm}$ DOS & 0.12 & Huffman et al. (2005) \\
\hline Laser vaporizer (upper limit) & $\leq 0.18^{\mathrm{c}}$ & this work \\
\hline
\end{tabular}

\subsection{Ambient particle beam width measurements}

Beam width probe measurements of ambient $\mathrm{rBC}$-containing particles provide insight into the morphology, and collection efficiency, of these particles. Ambient rBC particles sampled at $5 \mathrm{~m}$ height and $16 \mathrm{~m}$ from a roadside in downtown Toronto gave wider particle beams compared to those sampled away from large roadways, suggesting that fresh $\mathrm{rBC}$ emissions produce more divergent beams, and that particle processing reduces particle beam divergence (see Table 2). Both ambient BWP measurements indicated beam widths narrower than that of flame soot ( $\sigma=0.77 \mathrm{~mm}$ ) (Huffman et al., 2005), and fall within the range of ambient particle beam widths observed by Salcedo et al. (2007).

The similarity in beam width for the "fresh" $\mathrm{rBC}$ particles measured here and the beam width for bare Regal Black could suggest similar collection efficiencies for these types of particles. However, previous comparisons of SP-AMS rBC mass loadings with those derived from other instruments, such as the multiangle absorption photometer (MAAP), have suggested lower overall collection efficiencies for ambient rBC-containing particles (i.e. 0.1 to 0.3) (Massoli et al., 2012; Dallmann et al., 2014). Future ambient BWP measurements, in conjunction with comparison to other instruments, will further constrain the SP-AMS collection efficiency for ambient rBC and NR-PM.

Comparison of the estimated upper limit of laser beam width $(\sigma \leq 0.18 \mathrm{~mm})$ with ambient and laboratory particle beam width measurements highlights the relevance of incomplete beam overlap for SP-AMS quantification. It is important to note that this overlap mismatch is only relevant in the dimension perpendicular to the IR laser, such that a simple comparison of particle and laser beam widths is insufficient to provide a quantitative estimate of collection efficiency.

\subsection{Quantification of rBC mixing state in organic coated particles}

In order to quantify mixing state in terms of the mass fraction of rBC present in ambient aerosol the SP-AMS must be operated without the tungsten vaporizer to avoid interference from externally mixed NR-PM; however, in laboratory experiments when all particles are known to contain $\mathrm{rBC}$ such a quantification is possible. In this section, the ability of the SP-AMS to quantify mixing state for laboratory-generated internally mixed $\mathrm{rBC}$ particles is examined. It is important to note that these experiments focused on liquid organic coatings, which are similar to hydrocarbon-like organic coatings but may not resemble more oxygenated organic coatings present in ambient aerosol.

To accurately quantify rBC and NR-PM simultaneously from the same particles, it is important that the effective IR laser beam width for vaporizing all particle phase species is similar. If, for example, NR-PM could be vaporized in lower energy regions of the IR laser (i.e. at the edges of the beam) that do not effectively vaporize rBC, NR-PM would have a wider effective laser beam width. In such a case, the contribution of organic species to the overall particulate mass loading could be overestimated relative to $\mathrm{rBC}$ for $E_{\mathrm{S}}<1$. Figure $4 \mathrm{~b}$ demonstrates that the $\mathrm{rBC}$ and the organic signal transmission decrease with coating thickness in a similar manner when a BWP is placed in the centre of the particle beam. Furthermore, Fig. 2 demonstrates similar increases in $\mathrm{RIE}_{\mathrm{rBC}}$ and RIE $\mathrm{Org}$ with coating. Overall, these observations suggest that the effective IR laser beam width, in terms of its ability to vaporize different particle phase species, is similar for $\mathrm{rBC}$ and $\mathrm{BES}$.

To further assess the ability of the SP-AMS to quantify the mixing state of $\mathrm{rBC}$-containing particles, the mass fraction of Regal Black $\left(f_{\mathrm{RB}}=\operatorname{mass}_{\mathrm{RB}} /\left(\operatorname{mass}_{\mathrm{BES}}+\operatorname{mass}_{\mathrm{RB}}\right)\right)$ in BES coated particles of various $\mathrm{rBC}$ core sizes (40 to 


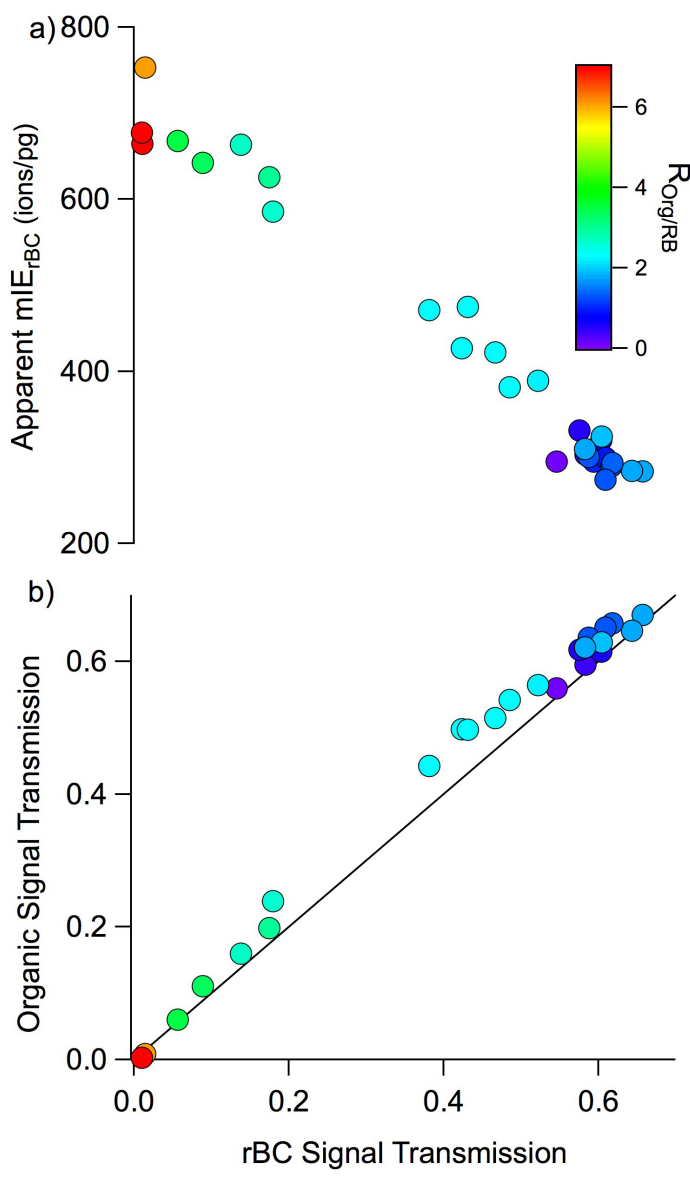

Figure 4. (a) $\mathrm{mIE}_{\mathrm{rBC}}$, app as a function of signal transmission with the beam width probe wire at the centre of the particle beam. The two sets of data were collected sequentially for each coating thickness by positioning the BWP wire outside the particle beam to measure $\mathrm{mIE}_{\mathrm{rBC}}$, app and then moving the wire into the centre of the beam to measure the associated signal transmission. Colours indicate organic coating thickness estimated from SP-AMS measurements of rBC and NR-PM (300 nm RB core). (b) Organic versus $\mathrm{rBC}$ signal transmission with a $0.41 \mathrm{~mm} \mathrm{BWP}$ wire at the centre of the particle beam, as a function of BES coating thickness $\left(R_{\mathrm{Org} / \mathrm{RB}}\right)$. The solid line represents a $1: 1$ relationship. Data from the ARI SPAMS (SN 215-039).

$300 \mathrm{~nm}$ mobility diameter) was measured with the SP-AMS and compared to $f_{\mathrm{RB}}$ obtained from particle mass measurements. Figure 6 demonstrates that $f_{\mathrm{RB}}$ values derived from the SP-AMS agree well with $f_{\mathrm{RB}}$ values from particle mass measurements when SP-AMS values are corrected for CE. The measured RIE app in this case is the product of the $\mathrm{RIE}_{\mathrm{rBC}}$ and $\mathrm{CE}$, where $\mathrm{RIE}_{\mathrm{rBC}}$ is the maximum ratio of the ions detected for $\mathrm{rBC}$ material sampled $\left(\mathrm{mIE}_{\mathrm{rBC}}\right)$, assuming all $\mathrm{rBC}$ particles vaporize in the laser beam, to the ions detected for ammonium nitrate $\left(\mathrm{mIE}_{\mathrm{NO}_{3}}\right)$. The $\mathrm{CE}$ factor, which is unity or less, is a measure of the missed $\mathrm{rBC}$ ion signal due to poor overlap between the particle beam and the laser vaporizer; that is, it accounts for $\mathrm{rBC}$ particles that miss the laser

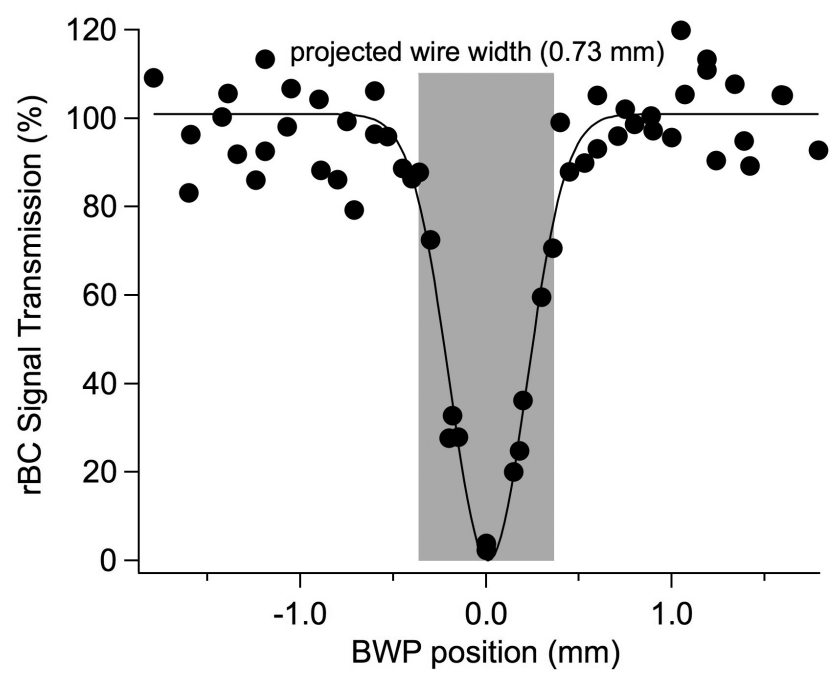

Figure 5. $\mathrm{rBC}$ signal transmission as a function of BWP position parallel to the laser beam axis of the SP-AMS. When the $0.46 \mathrm{~mm}$ BWP wire was placed in the centre of the particle beam, an average of $3 \pm 2 \%$ signal transmission was observed indicating that the effective beam width $(4 \sigma)$ is less than the projected width of the wire on the laser vaporizer (shaded region). This corresponds to a beam width $(\sigma) \leq 0.18 \mathrm{~mm}$. Data from the UofT SP-AMS using uncoated $300 \mathrm{~nm}\left(d_{\mathrm{m}}\right)$ Regal Black particles.

beam and are not vaporized. To obtain the corrected values, the upward trend in $\mathrm{RIE}_{\text {app }}$ measured for $\mathrm{rBC}$ and NR-PM with increasing coating thickness (Fig. 2) was fit to a sigmoid relationship to obtain the appropriate values for a given coating thickness (determined by mass analyser measurements for different $\mathrm{rBC}$-core sizes).

SP-AMS values derived using the $\mathrm{RIE}_{\mathrm{rBC}}$ for uncoated Regal Black and RIE Org $_{\text {gypically used for organics (i.e. } 0.2 \text { and }}$ 1.4 , respectively) can underestimate $f_{\mathrm{RB}}$ by up to $\sim 50 \%$ and data in Fig. 6 exhibit a pronounced non-linear relationship. For the specific case of BES, if the RIE ${ }_{\text {Org }}$ value is higher than the recommended value of 1.4 , the underestimation would be less than that depicted in Fig. 6. When RIE app values are corrected as described above the relationship in Fig. 6 shows excellent linearity $\left(R^{2}=0.98\right.$, slope $\left.=1.01 \pm 0.05\right)$.

These results indicate that the SP-AMS can accurately measure the fraction of Regal Black in laboratory generated organic coated particles, down to $f_{\mathrm{RB}}$ of $\sim 0.05$ for small (i.e. $40 \mathrm{~nm}$ ) inclusions, when instrumental sensitivity and CE are well known. The ability of the SP-AMS to quantitatively characterize $\mathrm{rBC}$ mixing state depends strongly upon the $\mathrm{RIE}_{\mathrm{rBC}}$, app and $\mathrm{RIE}_{\mathrm{Org}}$, app values used to calculate particulate mass loadings. In addition, knowledge of the value of $E_{\mathrm{S}}$, or particle loss owing to beam divergence, is essential for quantitative SP-AMS measurements of mixing state. Future ambient and laboratory beam width probe measurements may aid in determining $\mathrm{CE}$ for particles with unknown morphology and coating state. 


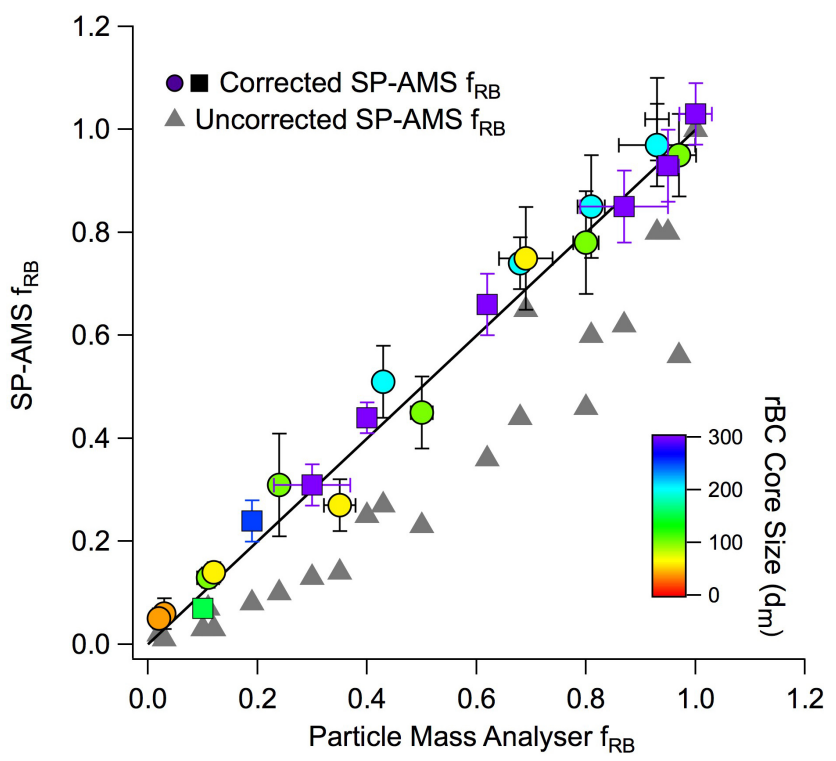

Figure 6. The fraction of Regal Black in BES coated particles $\left(f_{\mathrm{RB}}\right)$, obtained from SP-AMS mass loadings using uncorrected $\mathrm{RIE}_{\mathrm{rBC}}(0.2)$ and $\mathrm{RIE}_{\mathrm{Org}}$ (1.4) values (triangles) and RIE values corrected using the relationship observed in Fig. 2, plotted against $f_{\mathrm{RB}}$ obtained from particle mass measurements. Square points refer to RIE data shown in Fig. 2 that were used to determine the appropriate $\mathrm{RIE}_{\mathrm{app}}$ values to apply to data from separate experiments at various $\mathrm{rBC}$ core sizes (circles). A best-fit line to the data using corrected RIE values yields a slope of $1.01 \pm 0.05$ with $R^{2}=0.98$. The solid line represents a one-to-one relationship. Data from the UofT SP-AMS. Analogous plots for two ARI SP-AMS instruments are shown in Fig. S3.

\section{Summary}

Our results demonstrate that particle morphology affects the SP-AMS particle beam width, that in turn affects the collection efficiency through the overlap of the particle beam and the laser beam. Observations from laboratorygenerated internally mixed $\mathrm{rBC}$-containing particles in three SP-AMS instruments indicate that particle coating influences $\mathrm{CE}$ through beam divergence $\left(E_{\mathrm{S}}\right)$. We estimate $\mathrm{CE}$ for bare Regal Black particles, the recommended calibration material, to be $0.6 \pm 0.1$ suggesting that previous $\mathrm{rBC}$ calibrations of the SP-AMS with Regal Black were underestimated by up to a factor of 2. CE for ambient rBC-containing particles will depend on their morphology and the resulting particle-beam width, which is largely unconstrained. Future work will aim to empirically relate measurements of particle beam width to CE using a number of SP-AMS instruments, to provide a method to determine the $\mathrm{CE}$ of particles with unknown coating state.

Ambient BWP measurements indicate that fresh $\mathrm{rBC}$ containing particles sampled at the roadside in downtown Toronto have particle beam widths similar to, but greater than, bare Regal Black, and thus likely a collection efficiency less than bare Regal Black. More processed $\mathrm{rBC}$ particles have a smaller beam width and therefore a larger value of CE. The importance of measuring $E_{\mathrm{S}}$ is further highlighted by the upper limit estimate of the effective laser beam width for $\mathrm{rBC}$, from BWP measurements, of $\sigma \leq 0.18 \mathrm{~mm}$. Further work is required to provide an unambiguous measurement of the IR laser beam width, which could be applied in conjunction with ambient particle beam width measurements to provide a more specific estimate of CE in different sampling environments.

This work demonstrates for the first time the ability of the SP-AMS to quantitatively characterize the levels of internally mixed particulate $\mathrm{rBC}$ and NR-PM in laboratorygenerated particles over a wide range of compositions, when instrumental sensitivity is well known. In particular, the SPAMS can quantify the $\mathrm{rBC}$ mixing state even for highly organic-rich particles $\left(f_{\mathrm{RB}}<0.05\right)$ with atmospherically relevant $\mathrm{rBC}$ core sizes (i.e. $\geq 40 \mathrm{~nm}$ mobility diameter). The quantitative capability of the SP-AMS, combined with its ability to chemically characterize NR-PM coated on rBCparticles, can provide unique insight into the characteristics of ambient black carbon.

\section{The Supplement related to this article is available online at doi:10.5194/amt-7-4507-2014-supplement.}

Acknowledgements. The UofT research was supported by Environment Canada and NSERC. The UofT SP-AMS was purchased through a grant from the Canada Foundation for Innovation. The authors are grateful for Shao-Meng Li and John Liggio for the loan of the APM from Environment Canada. The ARI research was supported by DOE ASR \#DE-SC0006980, DOE SBIR \#DE-FG0207ER84890, NSF AGS-1244999, NASA SBIR \#NNX10CA32C, and NOAA Climate Program \#NA09OAR4310125.

Edited by: D. Toohey

\section{References}

Adachi, K., Chung, S. H., and Buseck, P. R.: Shapes of soot aerosol particles and implications for their effects on climate, J. Geophys Res.-Atmos., 115, D15206, doi:10.1029/2009JD012868, 2010.

Alfarra, M. R., Coe, H., Allan, J. D., Bower, K., Boudries, H., Canagaratna, M. R., Jimenez, J. L., Jayne, J. T., Garforth, A., Li, S. M., and Worsnop, D. R.: Characterization of urban and rural organic particulate in the Lower Fraser Valley using two Aerodyne Aerosol Mass Spectrometers, Atmos. Environ., 38, 5745-5758, 2004.

Bond, T. C., Bhardwaj, E., Dong, R., Jogani, R., Jung, S. K., Roden, C., Streets, D. G., and Trautmann, N. M.: Historical emissions of black and organic carbon aerosol from energy-related combustion, 1850-2000, Global Biogeochem. Cy., 21, GB2018, doi:10.1029/2006gb002840, 2007. 
Bond, T. C., Doherty, S. J., Fahey, D. W., Forster, P. M., Berntsen, T., DeAngelo, B. J., Flanner, M. G., Ghan, S., Kärcher, B., Koch, D., Kinne, S., Kondo, Y., Quinn, P. K., Sarofim, M. C., Schultz, M. G., Schulz, M., Venkataraman, C., Zhang, H., Zhang, S., Bellouin, N., Guttikunda, S. K., Hopke, P. K., Jacobson, M. Z., Kaiser, J. W., Klimont, Z., Lohmann, U., Schwarz, J. P., Shindell, D., Storelvmo, T., Warren, S. G., and Zender, C. S.: Bounding the role of black carbon in the climate system: a scientific assessment, J. Geophys. Res.Atmos., 118, 5380-5552, doi:10.1002/jgrd.50171, 2013.

Cappa, C. D., Onasch, T. B., Massoli, P., Worsnop, D. R., Bates, T. S., Cross, E. S., Davidovits, P., Hakala, J., Hayden, K. L., Jobson, B. T., Kolesar, K. R., Lack, D. A., Lerner, B. M., Li, S. M., Mellon, D., Nuaaman, I., Olfert, J. S., Petaja, T., Quinn, P. K., Song, C., Subramanian, R., Williams, E. J., and Zaveri, R. A.: Radiative absorption enhancements due to the mixing state of atmospheric black carbon, Science, 337, 1078-1081, 2012.

Corbin, J. C., Sierau, B., Gysel, M., Laborde, M., Keller, A., Kim, J., Petzold, A., Onasch, T. B., Lohmann, U., and Mensah, A. A.: Mass spectrometry of refractory black carbon particles from six sources: carbon-cluster and oxygenated ions, Atmos. Chem. Phys., 14, 2591-2603, doi:10.5194/acp-14-2591-2014, 2014.

Cross, E. S., Onasch, T. B., Ahern, A., Wrobel, W., Slowik, J. G., Olfert, J., Lack, D. A., Massoli, P., Cappa, C. D., Schwarz, J. P., Spackman, J. R., Fahey, D. W., Sedlacek, A., Trimborn, A., Jayne, J. T., Freedman, A., Williams, L. R., Ng, N. L., Mazzoleni, C., Dubey, M., Brem, B., Kok, G., Subramanian, R., Freitag, S., Clarke, A., Thornhill, D., Marr, L. C., Kolb, C. E., Worsnop, D. R., and Davidovits, P.: Soot particle studies - instrument inter-comparison - project overview, Aerosol Sci. Tech., 44, 592-611, 2010.

Dallmann, T. R., Onasch, T. B., Kirchstetter, T. W., Worton, D. R., Fortner, E. C., Herndon, S. C., Wood, E. C., Franklin, J. P., Worsnop, D. R., Goldstein, A. H., and Harley, R. A.: Characterization of particulate matter emissions from on-road gasoline and diesel vehicles using a soot particle aerosol mass spectrometer, Atmos. Chem. Phys., 14, 7585-7599, doi:10.5194/acp-14-75852014, 2014.

DeCarlo, P. F., Kimmel, J. R., Trimborn, A., Northway, M. J., Jayne, J. T., Aiken, A. C., Gonin, M., Fuhrer, K., Horvath, T., Docherty, K. S., Worsnop, D. R., and Jimenez, J. L.: Fielddeployable, high-resolution, time-of-flight aerosol mass spectrometer, Anal. Chem., 78, 8281-8289, 2006.

Huffman, J., Jayne, J. T., Drewnick, F., Aiken, A. C., Onasch, T. B., Worsnop, D. R., and Jimenez, J.: Design, modeling, optimization, and experimental tests of a particle beam width probe for the aerodyne aerosol mass spectrometer, Aerosol Sci. Tech., 39, 1143-1163, 2005.

Jacobson, M. Z.: Strong radiative heating due to the mixing state of black carbon in atmospheric aerosols, Nature, 409, 695-697, 2001.

Jansen, K. L., Larson, T. V., Koenig, J. Q., Mar, T. F., Fields, C., Stewart, J., and Lippmann, M.: Associations between health effects and particulate matter and black carbon in subjects with respiratory disease, Environ. Health Persp., 113, 1741-1746, 2005.
Jimenez, J. L., Jayne, J. T., Shi, Q., Kolb, C. E., Worsnop, D. R., Yourshaw, I., Seinfeld, J. H., Flagan, R. C., Zhang, X. F., Smith, K. A., Morris, J. W., and Davidovits, P.: Ambient aerosol sampling using the Aerodyne Aerosol Mass Spectrometer, J. Geophys. Res.-Atmos., 108, 8425, doi:10.1029/2001jd001213, 2003.

Lack, D. A., Langridge, J., Bahreini, R., Cappa, C., Middlebrook, A., and Schwarz, J. P.: Brown carbon and internal mixing in biomass burning particles, P. Natl. Acad. Sci. USA, 109, 14802-14807, doi:10.1073/pnas.1206575109, 2012.

Lack, D. A., Moosmuller, H., McMeeking, G., Chakrabarty, R. K., and Baumgardner, D. G.: Characterizing elemental, equivalent black, and refractory black carbon aerosol particles: a review of techniques, their limitations and uncertainties, Anal. Bioanal. Chem., 99-122, 2015-2029, doi:10.1007/s00216-0137402-3, 2014.

Liu, D., Allan, J., Whitehead, J., Young, D., Flynn, M., Coe, H., McFiggans, G., Fleming, Z. L., and Bandy, B.: Ambient black carbon particle hygroscopic properties controlled by mixing state and composition, Atmos. Chem. Phys., 13, 2015-2029, doi:10.5194/acp-13-2015-2013, 2013.

Massoli, P., Fortner, E. C., Canagaratna, M. R., Williams, L. R., Zhang, Q., Sun, Y., Schwab, J. J., Trimborn, A., Onasch, T. B., Demerjian, K. L., Kolb, C. E., Worsnop, D. R., and Jayne, J. T.: Pollution gradients and chemical characterization of particulate matter from vehicular traffic near major roadways: results from the 2009 Queens College air quality study in NYC, Aerosol Sci. Tech., 46, 1201-1218, 2012.

Olfert, J. S. and Collings, N.: New method for particle mass classification - the Couette centrifugal particle mass analyzer, J. Aerosol Sci., 36, 1338-1352, 2005.

Onasch, T. B., Trimborn, A., Fortner, E. C., Jayne, J. T., Kok, G. L., Williams, L. R., Davidovits, P., and Worsnop, D. R.: Soot particle aerosol mass spectrometer: development, validation, and initial application, Aerosol Sci. Tech., 46, 804-817, 2012.

Ramanathan, V. and Carmichael, G.: Global and regional climate changes due to black carbon, Nat. Geosci., 1, 221-227, 2008.

Salcedo, D., Onasch, T. B., Canagaratna, M. R., Dzepina, K., Huffman, J. A., Jayne, J. T., Worsnop, D. R., Kolb, C. E., Weimer, S., Drewnick, F., Allan, J. D., Delia, A. E., and Jimenez, J. L.: Technical Note: Use of a beam width probe in an Aerosol Mass Spectrometer to monitor particle collection efficiency in the field, Atmos. Chem. Phys., 7, 549-556, doi:10.5194/acp-7-549-2007, 2007.

Schwarz, J. P., Spackman, J. R., Gao, R. S., Perring, A. E., Cross, E., Onasch, T. B., Ahern, A., Wrobel, W., Davidovits, P., Olfert, J., Dubey, M. K., Mazzoleni, C., and Fahey, D. W.: The detection efficiency of the single particle soot photometer, Aerosol Sci. Tech., 44, 612-628, 2010.

Seinfeld, J.: Atmospheric science - black carbon and brown clouds, Nat. Geosci., 1, 15-16, 2008. 